\title{
PREPARING FOR FUTURE SECURITY CHALLENGES WITH PRACTITIONER RESEARCH
}

\author{
David LAST ${ }^{1}$, Travis MORRIS ${ }^{2}$, Bernadette DECECCHI ${ }^{3}$ \\ ${ }^{1}$ Royal Military College of Canada \\ ${ }^{2}$ Norwich University \\ ${ }^{3}$ Canadian Defence Academy
}

\begin{abstract}
Mid-sized countries face a changing security environment, and cannot be certain that the knowledge and practices of the past will serve the future. The officers, professors, and researchers in defence universities are the custodians of military sciences that must adapt to these changing situations. Practitioner research should be modelled and encouraged in defence universities as a vehicle for advancing military sciences to meet new challenges. Previous practitioner research in higher and adult education has highlighted the need for experiential learning in other professions. The authors report on practitioner research by professors at pre-commission military academies to improve cadets' understanding of peace and conflict. Military and police education is often experience-based, but there are few reports of practitioner research on its effectiveness, nor of combining peace and conflict education with out-of-classroom experiences. Legitimation Code Theory provides tools for understanding different teaching approaches. Comparing four cases of practitioner research on experiential learning the authors present models for practitioner research on teaching peace and conflict through out-of-classroom experiences, and conclude with means of evaluating learning experiences by pre-commission cadets, drawing on legitimation code theory. This is increasingly important for military academies striving to meet academic standards, but also to preserve professional values and young officer motivation to confront new challenges.
\end{abstract}

Keywords: Professional military education, practitioner research, future security, legitimation code theory

open Access (C) (i) () 2019 D. Last, T. Morris, B. Dececchi, published by War Studies University, Poland. This work is licensed under the Creative Commons Attribution-NonCommercial-NoDerivatives 4.0 License. 


\section{Introduction}

A military career of three or four decades can be expected to follow an unexpected path through a lot of change. We cannot know what future security challenges the students in today's defence universities will confront, but we have to do our best to prepare them for any eventuality. Our contention is that military sciences include experimentation. Every serious security practitioner must be a researcher and experimenter, testing new approaches to practical problems with an open mind. Inculcating and practicing this habit of inquiry should begin with pre-commission education and socialization. Experimentation becomes more important as operations become more demanding, and as education becomes more academic. Practitioner research, modelled and led by military and academic leaders, is a vital tool to prepare for future security challenges.

Practitioner research is conducted by individuals who work in a professional field rather than as full-time academic researchers, it encompasses action research, and stimulates experiential learning by individuals and by the larger profession within which it is conducted. While military science may have strategy and operational studies at its heart, the plural "sciences" implies a more catholic approach to the knowledge needed to confront future security challenges. After a turbulent three decades, the platitude that security problems have no military solutions is well established, and our future military leaders will need more than operational expertise to achieve security.

This paper will consider recent thinking about the challenges young officers today might be expected to confront over their careers. Theory and prior research suggest that practitioner research, action research, and experiential learning help professions to go beyond responding to change; effective professions can change societies to shape a better world. This should be our aspiration for the military profession. We report on four cases of practitioner research, and generalize about the ways in which defence universities can contribute to preparations to meet future security challenges. As military academies, staff colleges, and defence universities are pressed to meet academic standards, and as cadets and young officers spend more time in the classroom and less time in field training, it is vitally important to model and preserve the professional values of adaptability, resilience, and sceptical enquiry. We think that practitioner research will help to do this, and prepare young officers not only to meet future security challenges, but to shape the world in which we do so. 


\section{Future Security Challenges}

We have seen the future in the past, in glimpses of a turbulent present, and in trajectories of data. Forecasting future security environments is an industry, serving military, political, and economic clients, who have an interest in various readings of the tea leaves: industry sees wars demanding more sophisticated technology; humanitarians see crises requiring their efforts to prevent and mitigate; opportunistic politicians see ascending enemies. Mid-sized countries with limited military resources are challenged to preserve legacy capabilities for conventional conflict, while building knowledge, skills, and attributes for a wide array of new social, economic, and political challenges. Many emerging challenges have no obvious military solutions, but will inevitably engage military forces and leaders.

We can triangulate future visions articulated by small and large countries, international organizations, and academics, to produce a list of factors, actors, and conflicts summarized in Table 1. A more detailed analysis reveals important divergence between the perspectives and conclusions of various sources. Major powers focus on geopolitical trends, from which they reach conclusions about capabilities and actions to influence events. International organizations are more concerned about trends and actors, while small countries treat many of the major trends and anticipated changes as waves that must be surfed or endured rather than directed. Academics associated with defence institutions may write things for academic forums that don't make it into official projections (compare Gizewski, 2009 to Canada, 2014).

Pressure for higher education of military leaders over the last two decades arose in part from the challenge of addressing changes implied by Table 1 . The stable bipolarity of the Cold War, and the American hegemony of the 1990s and 2000s provided a backdrop for planning which some now view with nostalgia. If we can't make assumptions about our security environment, we have to study its changing nuances and think through our options and their consequences. Doing this requires higher education about complex systems, causes and effects. It requires honest knowledge of ourselves and our neighbours, who may be friends, rivals, and enemies, all at once. Higher education tends to be conducted in classrooms, but however good the view from the ivory tower, it is poor preparation for practice unless it is combined with experience. 


\section{Table 1. Summary of thinking about Future Security Challenges}

\begin{tabular}{|c|c|c|}
\hline Factors & Actors & Conflicts \\
\hline $\begin{array}{l}\text { - Complexity } \\
\text { - Urbanization } \\
\text { - Climate change } \\
\text { - Telescoping of strategic, } \\
\text { operational and tactical levels } \\
\text { - Interdependence } \\
\text { - Globalization + rule changes } \\
\text { (neo-liberalism and state } \\
\text { capitalism in conflict) } \\
\text { - Technology and innovation } \\
\text { leading to disruptive change } \\
\text { (cyber, ICT, robotics, AI) } \\
\text { - Demographic shift, with global } \\
\text { south as centre of gravity by } \\
2050\end{array}$ & \begin{tabular}{|l|} 
- US in relative decline \\
- China's rise and assertiveness \\
- Multi-polarity at regional and \\
global level \\
- Less salient and capable \\
international organizations \\
(but more necessary) \\
- Weak and failed states \\
- OSCE-NATO as two tracks, \\
but NATO weakness without \\
US \\
- Non-state commercial actors \\
increasingly important \\
- Non-state political, ideological, \\
and religious actors \\
- Criminalized political \\
structures
\end{tabular} & $\begin{array}{l}\text { - Conflicts over global commons } \\
\text { - Instability from... } \\
\text { - Economic and demographic } \\
\text { disruption } \\
\text { - Environmental disruption } \\
\text { - Mass migration for survival } \\
\text { and a better life } \\
\text { - Governance challenges } \\
\text { - Hybrid and unconventional } \\
\text { wars, shifting war/peace } \\
\text { boundaries } \\
\text { - Threats to civil populations } \\
\text { - Pandemics } \\
\text { - Weapons of mass destruction } \\
\text { or mass effects }\end{array}$ \\
\hline
\end{tabular}

Compiled from Bazin (2017); Gizewski (2009); Canada (2014); OSCE (2017); Stoltenberg (2016); Qi Dapeng (2015); Karlin (2018).

Disputes over global commons like the Arctic Ocean or the South China Sea, survival migration, climate change, and governance challenges from within or outside the state are not easily addressed by traditional military thinking. Escalation to war is unlikely to advance national or international security and inevitably undermines human security. For the majority of the world's states, the very idea that military forces exist primarily to fight and win wars must be re-evaluated. Yet military institutions retain that function. Junior officers in particular must be competent violent specialists (Tilly, 2003) before they become generalists capable of managing violence.

So how should we prepare the security leaders of mid-sized countries to understand changing factors and actors and prepare for the conflicts of the future? The factors, actors, and conflicts outlined in Table 1 generate wicked problems: there are no technical solutions; there is disagreement about the nature of the problems and the paths to solutions; and every effort to improve the situation generates new problems as actors adapt (Ritchey, 2011; Skaburskis, 2008). Practitioners have to understand the effects of their actions, design and adapt plans to rapidly changing reality, and understand the perspectives and objectives of multiple actors. Our contention is that prescriptions of content are insufficient. We must think about the form of higher education, and the means for adapting it to changing circumstances. From early in their careers, security 
leaders must research and adapt their practice. This paper is therefore written at two levels: it describes four examples of practitioner research; and it makes the claim that defence universities routinely engaging their students in practitioner research, action research, and experiential learning will generate knowledge and practice necessary for new security challenges.

\section{Theory and Research}

Experiential learning draws on the work of Lewin, Dewey, and Piaget. Piaget's four stages of learning (enactive, iconic, inductive, and hypothetico-deductive learning) recur throughout life in response to new experiences. Lewin describes a cycle of experience, observation and reflection on experience, testing the implications of concepts in new situations, and applying this to new experiences. Dewey, similarly, describes a series of impulses, observations, and judgements applied to new impulses, with progression driven by purpose. The essence of experiential leaning is that learning is a continuous adaptive process; it is not a series of fixed learned outcomes, each of which is resistant to change (Kolb, 1984). Lewis and Williams (1994) describe the rise of experiential learning as educators moved away from behaviourist notions of teachers purveying knowledge. Working on agricultural education, Knoblauch (2003) describes four tenets of experiential learning: learn in a real-life context; learn through projects; learn by doing; and learn by problem-solving. We think these are important insights for military professionals. They are common in mid-career staff colleges, but less evident at precommissioning military academies.

Military professional preparation includes: socialization to values and attitudes for service; training in predictable tasks for entry-level specialties; and education for critical thinking and problem solving. Socialization and training have evolved as practical pursuits, privileging action. Schaub (2014) has described the ratios of academic education, vocational training, and leadership in pre-commission programs in 28 European states. Academic content has tended to increase as institutions seek to emulate civilian standards for professional education. Education in degree-granting or university-like institutions, however, has included primarily classroom delivery, following the conventions of traditional university education. The result is that experiential learning has been traditionally focused on training in tactical tasks, while the broader 
understanding and habits of mind developed through education have been inculcated in classrooms in programs that mimic civilian universities. Data collected by Gary Schaub of Denmark show that only 8 of 73 European military educational institutions do not offer degrees (Figure 1, derived from Schaub's data). Driven by requirements of degrees, cadets and officers are now spending a lot of time in classrooms, although many of the most important learning objectives can only be met through appropriately guided and tested experience. Practitioner research can help us to rebalance this.

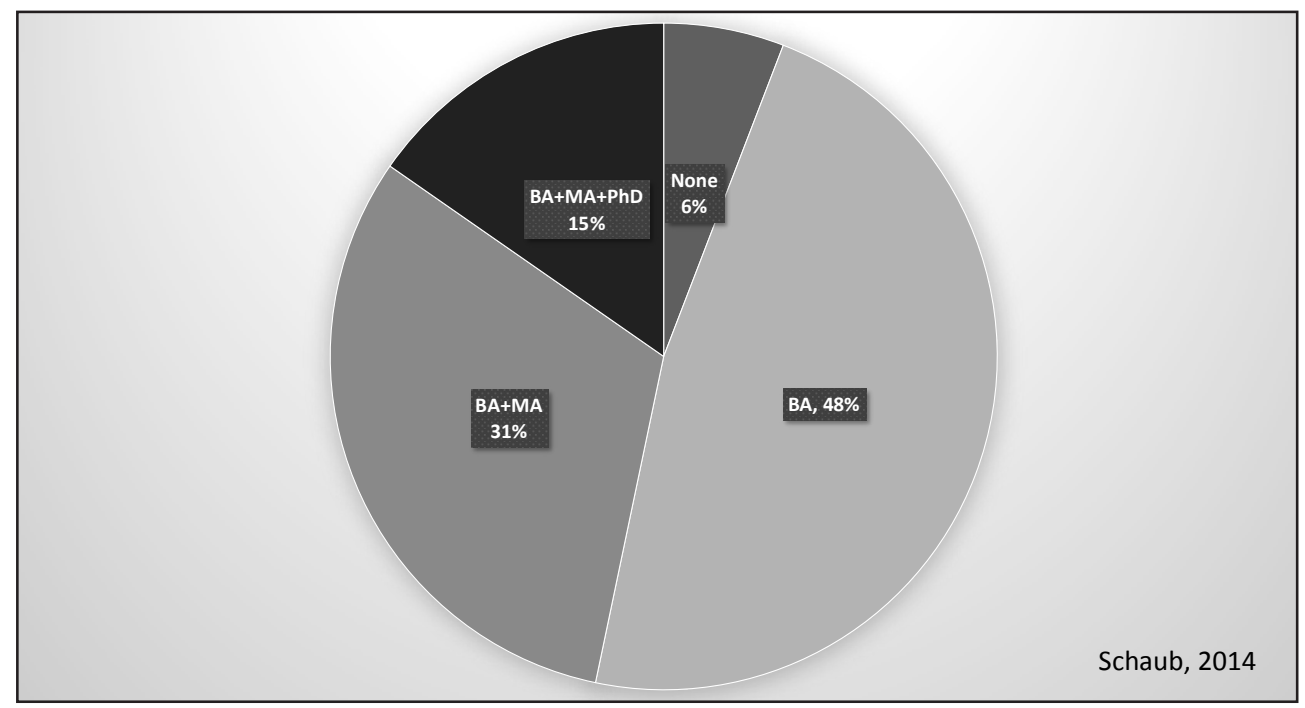

Fig. 1. Percentage of European Military Education Institutions offering Degrees at each level

A consensus is emerging in staff colleges that the challenges of contemporary and anticipated security environments cannot be adequately addressed by traditional, linear operational planning processes (Lauder, 2009). Drawing on insights from the private sector and operational experience, ideas about design are increasingly finding their way into mid-career and senior officer education. ${ }^{1}$ However, discussions about teaching these ideas to military audiences seem divorced from wider discussions of higher education and adult learning found in sociology and education faculties. This is true more broadly

1 Exploring this contention is beyond the scope of this article, but see, for example work by Ben Zwiebelson, and the web site, Military Epistemology, http://militaryepistemology.com/author/ benzweibelson/ 
of military sciences research, which is often isolated by the structural specialization of the military. We have found no reports of practitioner research on the effectiveness of military education, even when novel approaches like design thinking are introduced. In a world of complex adaptive systems, design thinking for solutions, and rapidly evolving professional responsibilities, we need better tools to understand military teaching and learning to prepare for future security challenges.

Legitimation Code Theory (Maton 2014) is a rapidly growing approach to the study of education, knowledge and practice. It draws on insights from Pierre Bourdieu's field theory and Basil Bernstein's work on codes in education to offer a framework for research and practice that helps to overcome the fragmentation of disciplines and professions (Maton et al. 2016). It provides tools for understanding different teaching and learning approaches that characterize educational experiments, and we have to admit that all education is experimental. Understanding the impact of our educational efforts, and engaging the professional subjects of those efforts, will help the military profession go beyond responding to change, to shape social responses with the aim of managing violence and reducing conflict, in the same way that health professions have advanced prevention, and educators have improved learning.

\section{Practitioner Research}

Practitioner research involves individuals who work in a professional field rather than as full-time academic researchers. Parameters for practitioner research have been explored most consistently in the fields of health, education, and social care (Campbell and Groundwater-Smith 2007). These professions have not just prepared for future challenges; they have been able to change the environment in which they operate, achieving dramatic advances within living memory. University professors sit in both academic and practical worlds - researching within their discipline as academics, but also teaching, with responsibility for student learning outcomes. University teachers in military academies and staff colleges have additional responsibilities to the security professions. Both a professional body of knowledge and professional values and ethics are shaped through socialization, education and training that occurs at these institutions. This is not news to the reflective professionals teaching there. Through daily interaction with their students in uniform, frequently through contact with former students, and 
occasionally at funerals and memorial services, the connection between professional education and service is regularly reinforced. The authors have served and teach those who will. We are researchers in our own fields, relevant to security, and we are concerned about the competencies of our students to engage in the professions that we have served.

Our guidance on practitioner research protocols in education comes from Anderson et al. (2007), Campbell and Groundwater-Smith (2007), Campbell et al (2004), and Menter et al (2011). The ethical aspects of field studies in particular presented challenges to the Institutional Review Board (Norwich University) and the Research Ethics Board (Royal Military College) $)^{2}$.

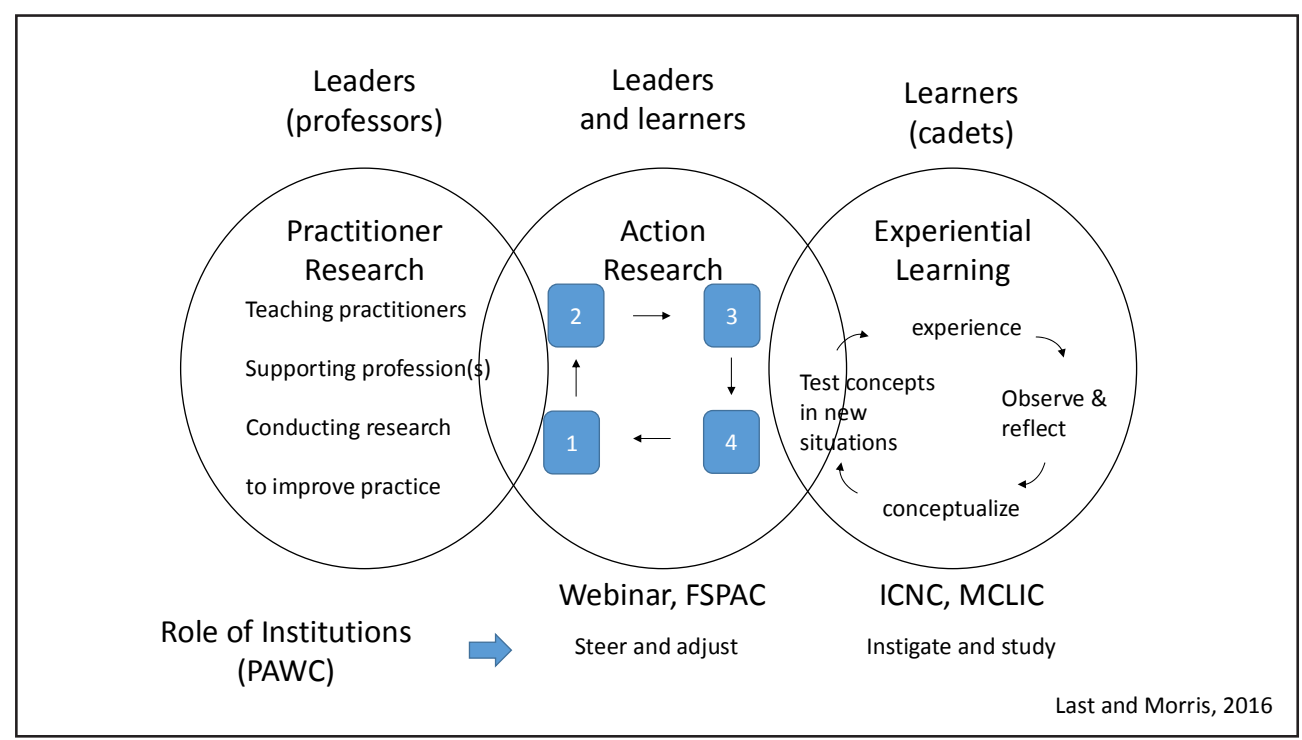

Fig. 2. Peace and War Centre (PAWC) Research and Teaching

Figure 2 illustrates the context of four separate educational activities: a student-led webinar, Field Study in Peace and Conflict (FSPAC), a seminar sponsored by the International Centre for Non-Violent Conflict (ICNC), and a multicultural leadership immersion experience (MCLIC). These four activities can be taken together as international practitioner research because of the context in which they occurred, sponsored by the

2 The RMCC Research Ethics Board (REB) and Norwich University Institutional Review Board (IRB) submissions and related correspondence are available on ResearchGate at https://www. researchgate.net/project/Field-Studies-in-Peace-and-Conflict?updateId=57fcabb908ae9ca0c5ca3a2b 
Peace and War Centre at Norwich University. The first authors are former military and police professionals working through the Centre, with the assistance of an educational specialist at the Canadian Defence Academy. They are practicing university teachers, supporting the development of young professionals in two institutions dedicated to professional development, conducting research to improve practice. The subject of the practitioner research is therefore not just each event, but the interaction of all the events in their institutional setting, including the achievements and limitations of action research and experiential learning.

Action research is usually initiated to solve a specific problem identified within a community of practice, and often involves progressive problem solving: why aren't we getting the results we expect? What if we do this? Did it work? How about changing something? (Sagor 2011). Action research proceeds as a spiral series of action cycles:

1. Develop a plan of action to improve what is already happening. In both cases (the webinar and FSPAC), our aim was to increase the role of students in planning their own learning experiences;

2. Act to implement the plan. This entailed prompting the students to act within the constraints of an academic year and its associated activities;

3. Observe the effects of the action in the context in which it occurs. This entailed professor working with and observing students as they conducted planning and execution of educational tasks (the webinar and the FSPAC);

4. Reflect on the effects as a basis for further planning and subsequent action. Each of the four events has the potential for repetition at Norwich and RMC, and replication in other settings.

The webinar and FSPAC are examples of action research because they were initiated to solve specific problems and repeated the cycle described by Sagor (2011). Each event addressed problems at two levels: an immediate question of educational shortfall (are cadets learning what they need to know about peace and conflict as professionals?); and an encompassing question of pedagogy (can cadets learn better through the experience of guiding their own learning?). The cycles of student-professor interaction during the events, and reflective reporting of experiences for application to planned future events is typical of action research. The FSPAC also presented the opportunity to study student experiential learning, treating the participants as subjects of research, rather than partners in the conduct of action research. This would have required ethics and 
institutional review approval, which was not obtained in time, but might be included in future iterations.

The ICNC seminar and MCLIC experience did not entail repeated cycles of observation and adjustment by professors within the events. Professors initiated and studied participation in the ICNC seminar and Macedonian Summer Campus but the cycle of experience-observation/reflection-conceptualization-testing (Kolb 1984) was internal to the students participating. In the case of the ICNC seminar, the authors were able to test before and after the event, and one author observed during the event, but the events themselves could not be adjusted experimentally as in the case of action research.

\section{Data and Methods}

Data were in the form of documents produced by the students (social media posts, journals, reports), discussions with students, direct observations, and triangulation of sources (Stewart 1998). Data were collected from four events:

- Webinar. A cadet-initiated and cadet-led webinar with senior Reserve Officer Training Corps (ROTC) leaders in six private universities with well-established ROTC programs. The webinar resulted in a briefing note and leadership panel discussion (one cadet in preparation, approximately 450 cadets in event audience, two instructors involved in analysis)

- FSPAC. A Field Study of Peace and Conflict in Israel-Palestine was organized and conducted by cadets under faculty supervision, experimenting with several different engagement techniques, and culminating in a handbook for the conduct of cadet-led field studies in peace and conflict (six American cadets, one Canadian reservist, one Canadian civilian, two instructors)

- ICNC Workshop. International Centre for Nonviolent Conflict seminar on nonviolent civil resistance (three Canadian Cadets, one Canadian officer, one American Cadet, one cadet from a third country, one instructor)

- MCLIC. The Multicultural Leadership Immersion Course (MCLIC) is a proposal, and the Macedonian Summer Campus (attended by two American ROTC Cadets) provides relevant data from interviews with participants.

Analytical methods included a before-and-after questionnaire using SurveyMonkey (ICNC), participant observation (ICNC, Webinar, and FSPAC), discourse analysis 
(Webinar), and content analysis (all). Content analysis applied Legitimation Code Theory (Maton 2014, Maton 2016). Maton (2014) describes five legitimation codes: Autonomy, Density, Specialization, Semantics, and Temporality. Here we use specialization codes to describe the categories of knowledge sought by cadets engaged in self-directed learning outside the classroom, and the kinds of knowledge about conflict and cross-cultural communications that they found most compelling.

"Knowledge is both a structured and structuring structure," (Maton 2014, p. 28) implying, inter alia, that how we organize what we know shapes how we learn. For each event, we considered the kinds of knowledge to which cadets were exposed, and the social relations implied by the sought-after expertise. Figure 3 presents Maton's Specialization Plane. Social relations emphasize who is a legitimate purveyor of knowledge-who you are matters more than what you know. Epistemic relations emphasize what you know-specific kinds of formal knowledge are privileged, like calculus or computer programming. Elite knowledge combines both specialized knowledge and special status, and relativist knowledge requires neither specific knowledge nor special status. The distinctions aren't sharp, but the relative emphasis shifts in each quadrant of the plane.

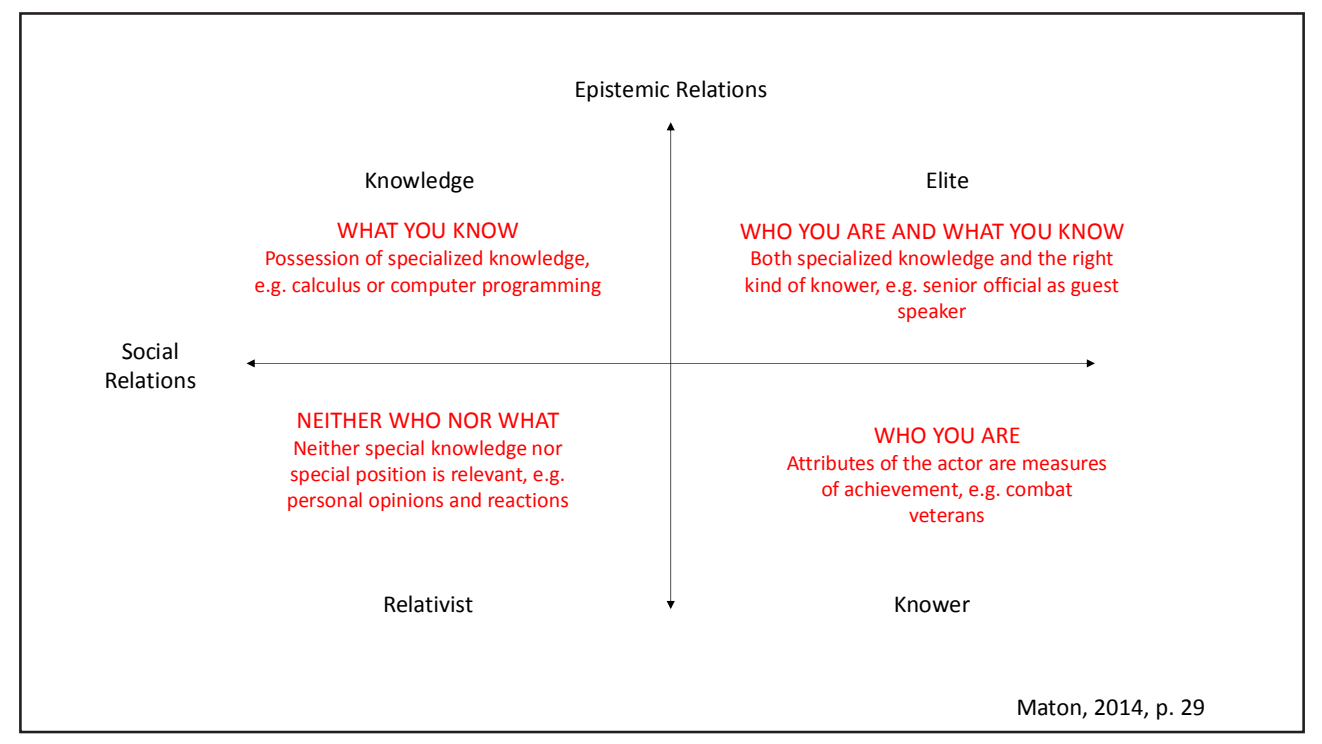

Fig. 3. Maton's Specialization Plane 


\section{Comparing Four Cases}

Learning about conflict entails understanding those who are not like us. This requires competence in communicating across cultural differences. These skills are broadly understood as cross-cultural competencies (Bennett 1986). The Webinar event began with a cadet initiative to hold a multi-institution conference on education for effective cross-cultural competencies (3C) in support the $100^{\text {th }}$ anniversary of the American Reserve Officer Training Corps (ROTC) held at Norwich University in 2016. Initial cadet expectations were ambitious, unrealistic, and unfunded. Professor Morris used the sponsorship of the Peace and War Centre to help the cadet instigator to adjust expectations, find solutions to logistics, technical and resource constraints, and understand the rules and procedures of the organizations involved. These included Norwich University and the five other institutions (Virginia Military Institute, Virginia Tech, Georgia Tech, The Citadel, Texas A\&M, and Mary Baldwin College), the ROTC command, and the larger world of the US armed services and Department of Defence.

The cadet choice of targets for the Webinar was constrained by practical considerations. Early discussions had considered a much wider participation of cadets and educators, but costs prevented travel, and web technology permitted only one outstation per institution (three institutions each in two sessions). It would have been possible to consult cadets or academic experts, but the preference was for experienced practitionersthe senior officers responsible for ROTC in each of the institutions. This choice was revealing. Cadets in general seemed to find practitioner knowledge about cross-cultural communication more compelling and relevant than academic knowledge. The "knower" basis of knowledge for the webinar contrasts with a knowledge-based framework for understanding cross-cultural competencies. If the interlocutors had special knowledge of $3 \mathrm{C}$ education, the webinar would have reflected elite knowledge (upper right quadrant), but this was not the case. Only their status as ROTC leaders qualified discussants. Education researcher Jodie Martin comments that cadets may have been knowledgeblind; unable to see epistemic relations, they focused on social relations.

The Webinar was different from a typical military staff exercise to develop educational materials, because it originated with ROTC cadet queries about the effectiveness and accessibility of education to improve cross cultural competence. Cadet questions implied that their experience as young people, not yet fully socialized to military service, differed from the experiences of the older, fully socialized, professionals responsible for 
enhancing cross-cultural competencies. Researchers got the impression from ROTC commanders that whatever the question was, the answer was, "what we're doing now." Some cadets, on the other hand, were less impressed with "what we're doing now." In this relationship, we find a stereotypical institutional conservatism, with an older generation invested in current practice which has been serviceable during their careers, and a younger generation ready to question and change practice. ${ }^{3}$ Preparing for future security challenges may require ceding some control to a younger generation, but they will need guidance on how to test their ideas.

Cycles of learning from the field study in peace and conflict (FSPAC) were more complex than those for the webinar because faculty supervisors (the authors) were explicitly learning in each phase of the field study, and comparing and adjusting their expectations. The field study has been repeated twice since the initial 2016 experiment, and each team has learned from its predecessors. Conceiving the project, setting and adjusting the objectives, recruiting and selecting participants, initiating preparations by the participants, supervising the planning and execution of activities, and observing and interpreting student learning were cycles involving regular interaction between Canadian and American cadets and the authors. For participating cadets, cycles of learning were: personal and team preparations for the trip; planning and conducting team engagements (each involving preparation, participation, and processing); and post-trip processing. A new cycle of learning occurs as participants consolidate their experiences to transmit them to the next group.

The variety of different engagement types in the field study can be plotted according to specialization codes. Engagements for which both specialized knowledge and high status are required are in the first quadrant in Figure 3, e.g. experts invited to the conference including speakers from the US Embassy, the Government of Israel, and the Palestinian authority. A meeting with the Egyptian Ambassador also fell in this quadrant. Briefings from organizations typically rely on expert knowledge particular to that organization, and fall in the second quadrant. Community representatives at the conference, impromptu talks, tours presenting community perspectives, and street engagements typically reflect neither special expertise nor particular social position, and are the most relativist of the information sources to which participants were exposed. These also presented the

3 A longer report of this research describes each event in greater detail, and is available from the authors on request. 
greatest challenge for participants to process, because they did not have immediate reference points or frameworks. They were forced to ask themselves, "where is this perspective coming from? What interests does it reflect?" Relativist perspectives forced participants to parse critically the narratives and assertions that they were hearing in an unfamiliar environment, and we think they provided some of the most valuable learning about conflict perspectives from the field study. Solicited talks and formal conferences involved political actors with well-honed and persuasive arguments, which demanded difficult reflection and critical analysis by the participants.

Our findings about how cadets learned during the ICNC workshop are relevant to the interface between non-violent strategies and state security, particularly strategies of confrontation and national survival for smaller states. We found that both self-reported and demonstrated understanding increased as a result of the workshop. Preparatory materials alone had little impact. Attitudes towards non-violent civil resistance were more thoughtful and strategic after the seminar. A cadet from an Asian state, for example, discussed the role of non-violent civil resistance in the resilience of democratic regimes and resistance to foreign aggression. Military participants appear to have identified with both resistance and security forces, and demonstrated thinking about means of countering non-violence, as well as employing it. This may help to explain why ICNC research finds diminishing effectiveness of non-violent civil resistance since 2006 (Bartkowski 2016). Imbued with a strategic, problem-solving mindset from early in their careers, "violent specialists" (Tilly 2003) adapt to new challenges like non-violent civil resistance. 


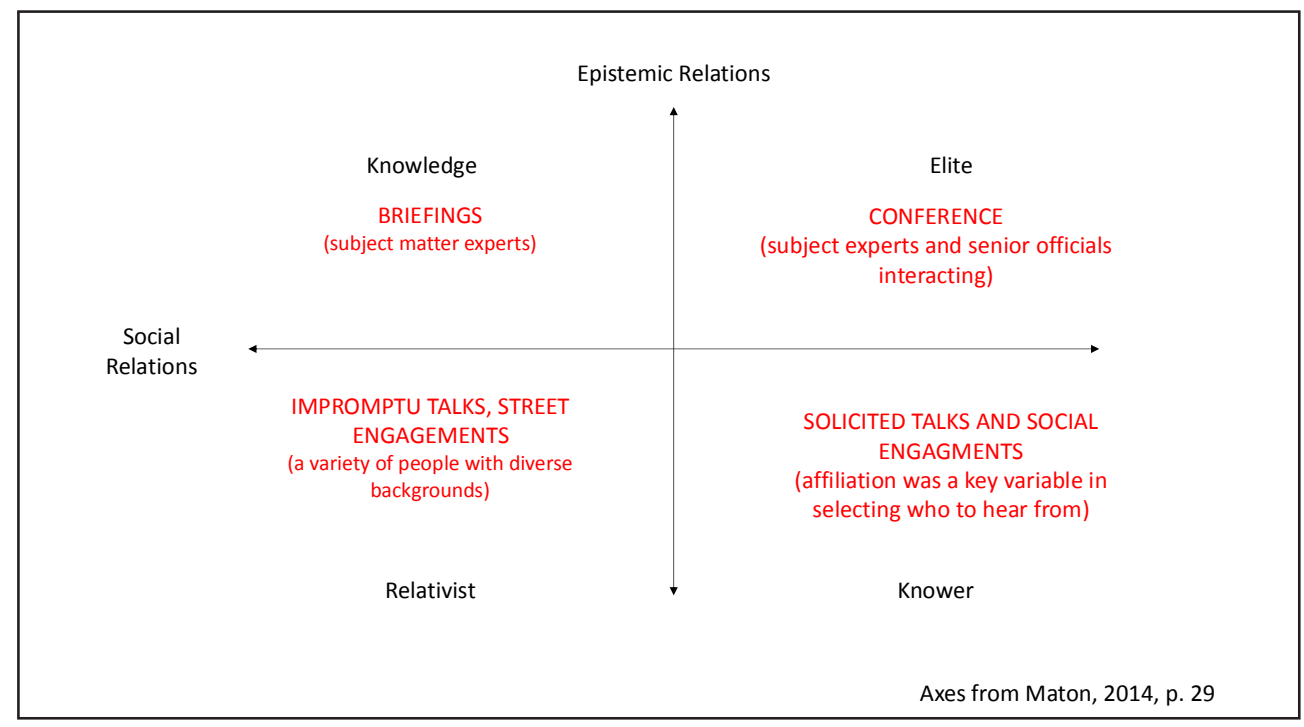

Fig. 4. Specialization Plane for Field Study Engagement Types

Specialization codes can be used to identify the kinds of knowledge that cadets found most compelling in the ICNC seminar. In discussions, the academic CVs of presenters were not initially impressive, but their "street credibility" grew with the stories of real situations recounted in their presentations. The older cadets and the military graduate student found presenters and reading material in the "knowledge" quadrant more compelling, but the younger cadets seemed to focus on the action stories of the knowers.

The Multi-Cultural Leadership Immersion Course (MCLIC) is an innovative combination of summer school and field exercise for young leaders. It includes lectures by academic experts (phase I), field exercises and workshops (phase II), cultural site visits (phase III), and a culminating multinational exercise (phase IV). These four phases encompass all four specialization codes: academic expertise (phase I) is in the 'knowledge' quadrant; personal knowledge from small group work (both discussions in phase I and workshops and exercises in phase II) fall in the 'relativist' quadrant; cultural visits drawing on local knowledge (phase III) fall in the 'knower' quadrant; academic practitioners (phase I) and feedback from senior officers with crosscultural experience (phase IV) fall in the 'élite' quadrant. Collaboration with faculty from the Macedonian Military Academy to develop a new team multi-cultural competency assessment tool (MCTA) also falls in the 'élite' quadrant, relying on both professional experience and academic expertise. This description overstates the separation of the 
specialization codes, which are much more fluid and integrated in practice. The MCLIC has not yet been realized, but reports from participants in the 2016 Macedonian Summer Campus (with similar characteristics) suggest that it has the potential to have a profound impact on cadets' abilities to communicate and lead in complex, conflictprone environments.

\section{Conclusions}

How does practitioner research help prepare for future security challenges? Maton's Specialization Plane helps to describe the kinds of knowledge and knowers that are privileged in different kinds of educational experiences. How we structure knowledge can privilege old ideas and old ways of doing things, or it can open institutions to new influences: knowledge is both a structured and structuring structure. The webinar revealed a sceptical enquiry by the younger generation, and some resistance to change by those responsible for established programs. The discourse about what and how young officers should learn can be changed by student-led experiences; the next generation may be better able to adapt to future challenges. The field study in Israel/Palestine and the Macedonian Summer Campus illustrate programs that provide a rich variety of experiential learning about the dynamics of complex protracted conflicts, and difficult collaborations. Finally, the workshop on non-violent civil resistance challenged cadets and young officers to engage with different ways of thinking, and to think strategically about alternatives to violence. These can be thought of as the first order effects of action research and experiential learning. While we were observing the students, however, they were observing us. Practitioner research in any branch of military sciences helps to model reflective practice. To address future security challenges, we cannot be mere purveyors of knowledge, because the knowledge we need to address those challenges does not yet exist. Our aspiration as professionals should be to change societies to shape a better and safer world, through experimentation integrated in our practice.

Acknowledgements: The research supporting this article was conducted with the assistance of Fulbright Canada funds, the Peace and War Centre of Norwich University, and Olmsted Foundation funds. The authors are grateful for comments and assistance from Jodie Martin and numerous colleagues. 


\section{Bibliography}

Anderson, G.L, Herr, K., and Nihlen A.S., 2007. Studying Your Own School: An Educator's Guide to Practitioner Action Research, SAGE Publications, Thousand Oaks.

Bartkowski, M.J. (2016). "Non-Violent Defence in National Security," Non-Violent Civil Resistance Workshop. Presentation at University of Toronto, 26 February.

Bazin, A., 2017. The Future Security Environment: An Emerging View, Vojenské rozhledy: Mimořádné číslo.

Bennett, J.M. 1986. Modes of cross-cultural training: Conceptualizing cross-cultural training as education. International Journal of Intercultural Relations, 10(2), 117-134.

Campbell, A., McNamara O. and Gilroy P., 2004. Practitioner Research and Professional Development in Education, Paul Chapman, London.

Campbell A., Groundwater-Smith S. (eds), 2007. An Ethical Approach to Practitioner Research: Dealing with Issues and Dilemmas in Action Research, Routledge, London.

Canada 2014. The Future Security Environment, 2013-2040, Department of National Defence, Ottawa.

Gizewski P.J., 2009. Army 2040: The Future Security Environment: Emerging Trends and Potential, Canadian Political Science Association.

Karlin, M., 2018. "Order from Chaos: How to Read the 2018 National Defence Strategy" Brookings, 21 January.

Knobloch, N.A., 2003. Is experiential learning authentic? Journal of Agricultural Education, 44(4), 22-34. [online] Available from: https://www.researchgate.net/ profile/Neil_Knobloch/publication/228497672_Is_experiential_learning_authentic/ links/5499e2d00cf21eb3df60e08d.pdf [Accessed 30 Nov 2018].

Kolb, D.A., 1984. Experiential learning: Experience as the source of learning and development., Prentice-Hall, Englewood Cliffs, NJ. [online] Available from: https://www.researchgate. net/profile/David_Kolb/publication/235701029_Experiential_Learning_Experience_ As_The_Source_Of_Learning_And_Development/links/00b7d52aa908562f9f000000/ Experiential-Learning-Experience-As-The-Source-Of-Learning-And-Development.pdf [Accessed 30 Nov 2018].

Lauder, M., 2009. Systemic Operational Design: Freeing Operational Planning from the Shackles of Linearity. Canadian Military Journal, 9:4.

Lewis, L.H., Williams, C.J., 1994. Experiential learning: Past and present. New Directions for Adult and Continuing Education, (62), 5-16. [online] Available from: http://www.sunyjcc.edu/ sites/default/files/Experiential-Learning-Past-and-Present.pdf [Accessed 30 Nov 2018].

Maton, K., 2014. Knowledge and Knowers: Towards A Realist Sociology of Education. Routledge, New York.

Maton K., Hood S. and Shay S. (eds), 2016. Knowledge-building: Educational studies in Legitimation Code Theory. Routledge, New York.

Menter, I., Elliot, D., Hulme, M., Lewin, J. and Lowden, K. 2011. A guide to practitioner research in education. Sage, Boulder CO. 
OSCE 2017. Renewing Dialogue on European Security: A Way Forward (Report on outreach events of the Panel of Eminent Persons on European Security as a Common Project in 2016. OSCE, Brussels.

Qi Dapeng 2015. The Profoundly Evolving International Landscape and China's International Strategy: A General Review of the International Strategic Situation and China's National Security. In International Strategic Relations and China's National Security, Volume 1. Institute for Strategic Studies, National Defence University, Singapore.

Ritchey, T., 2011. Wicked Problems - Social Messes: Decision Support Modelling with Morphological Analysis. Springer, Berlin.

Sagor R., 2011. The Action-Research Guidebook: A Four-Stage Process for Educators and School Teams, second edition. Sage, Boulder CO.

Schaub, G., 2014. Military Education 4: European Trends, University of Copenhagen, 23 June. (communication with author)

Skaburskis A., 2008. "The Origin of 'Wicked Problems'” Planning Theory and Practice, 9:2, 277280.

Stewart A. 1998. The ethnographer's method (Vol. 46). Sage.

Stoltenberg J., 2016. Panel discussion with NATO Secretary General Jens Stoltenberg at the Brussels Forum, organized by the German Marshall Fund of the United States, NATO.

Tilly C., 2003. The Politics of Collective Violence. Cambridge, UK: Cambridge University Press.

\section{Authors:}

David Last, PhD

Royal Military College of Canada

https://orcid.org/0000-0003-0447-4214

Travis Morris, $\mathrm{PhD}$

Norwich University

https://orcid.org/0000-0001-7703-4952

Bernadette Dececchi, PhD

Canadian Defence Academy 